\title{
Functional changes in piriform cortex pyramidal neurons in the chronic methamphetamine-treated rat
}

\author{
Nobuaki Hori ${ }^{1}$, Tomoko Kadota ${ }^{2}$ and Norio Akaike ${ }^{1,3}$ \\ 1 Research Division for Life Sciences, Kumamoto Health Science University, Izumi 325, Kita-ku, Kumamoto City, Kumamoto \\ 861-5598, Japan \\ 2 Department of Bioenvironmental Medicine and Anatomy, Chiba University, Graduate School of Medicine, Chiba 260-8670, \\ Japan \\ 3 Research Division for Clinical Pharmacology, Medical Corporation, Jyuryokai, Kumamoto Kinoh Hospital, 6-8-1 Yamamuro, \\ Kitaku, Kumamoto, 860-8518, Japan
}

\begin{abstract}
Chronic treatment of rats with methamphetamine (MAP) causes a range of functional changes to the central nervous system (CNS), including a toxicity that is widespread throughout the brain (Frost and Cadet 2000; Fasihpour et al. 2013). In this report, we examined the effect of chronic MAP treatment on pyramidal neurons of the rat piriform cortex, an area involved in sensory processing, associative learning and a model system for studies on synaptic plasticity. MAP treatment significantly depolarized the membrane potential and decreased neuronal input resistance. Furthermore, the voltage-dependence of both AMPA and NMDA responses was disturbed by chronic MAP treatment, and the extent of long-term potentiation (LTP) was decreased. Morphological changes of MAP-treated rat pyramidal neurons were observed as blebbing of the dendrite trees. The changes we observed represent detrimental effects on the function of piriform cortical neurons further illustrating deficits in synaptic plasticity extend beyond the hippocampus. These changes may contribute to behavioural deficits in chronic MAP-treated animals.
\end{abstract}

Key words: Methamphetamine - Rat piriform cortex - AMPA - NMDA - LTP

\section{Introduction}

Methamphetamine (MAP) and its derivatives, 3,4 methylenedioxymethamphetamine (MDMA, "ecstasy") and 3,4-methylenedioxyamphetamine (MDA), are powerful psychostimulant drugs of abuse. Chronic and/or excessive doses cause impaired memory and learning (Schröder et al. 2003; Goncalves et al. 2012) and other mental diseases (Fasihpour et al. 2013) including addiction. Addiction to MAP and the associated symptoms of disorientation and increased aggressiveness have become a social problem (Rusyniak 2013).

There is evidence that neurotoxicity and the neuronal disorders associated with chronic MAP involves altered

Correspondence to: Norio Akaike, Research Division for Life Sciences, Kumamoto Health Science University, Izumi 325, Kita-ku, Kumamoto City, Kumamoto, 861-5598, Japan

E-mail: akaike@kumamoto-hsu.ac.jp function of dopamine and NMDA receptor signaling pathways (Frost and Cadet, 2000; Moriguchi et al. 2002; Ishikawa et al.2005). MAP-induced sensitization and neurotoxicity, for example, can be blocked by NMDA receptor antagonists (Ohmori et al. 1994; Thomas and Kuhn, 2005). The physiological mechanisms underlying the disability of memory and learning with chronic MAP treatment have largely focused on the rat hippocampus (Ohmori et al. 1994; Hori et al. 2010; Han et al. 2012) and neostriatum (Moriguchi et al. 2002). Activation of NMDA receptors in rat hippocampal slices mediates long-term potentiation (LTP) at Schaffer collateral to CA1 neuron synapses (Hori et al. 2010; Swant et al. 2010), and this form of synaptic plasticity is believed to be an important aspect of the early stages of the formation of some types of memory (Lynch 2004). Chronic MAP treatment is associated with reductions in hippocampal LTP (Ohmori et al. 1994; Swant et al. 2010). 
The present study extends these studies on the electrophysiological and morphological effects of chronic MAP to the pyramidal neurons of the rat piriform cortex, a region that receives fibers directly from the olfactory bulb and has a well-defined neuronal architecture, similar to that in the hippocampus (Hori et al. 2010). Coupled with the defined role of the piriform cortex in olfactory processing and learning, the piriform cortex is also a suitable region for the study of synaptic plasticity (Linster and Hasselmo 2001). Furthermore, the piriform cortex may be particularly relevant to behavioral models of stereotypical behavior that accompanies chronic MAP abuse. Rats sensitized to amphetamine display a stereotyped abnormal sniffing behavior (Kitanaka et al. 2009) that may involve alterations in piriform cortex function. Furthermore, there are little previous electrophysiological and morphological studies on pyramidal neurons in piriform cortex of MAP sensitized rats. Therefore, we chronically treated mature rats with MAP and investigated changes in both morphological properties, and of intrinsic neuronal properties (membrane potential, membrane resistance) and synaptic physiology and plasticity (LTP, and sensitivity of NMDA and AMPA receptors).

\section{Materials and Methods}

\section{Chronic MAP treatment}

All experiments were performed in accordance with The Guiding Principles for Care and Use of Animals in The Field of Physiological Society of Japan. As shown in the experimental protocol schematic of Fig. 1, male SpragueDawley mature rats (body weight about $250 \mathrm{~g}$ ) were treated with MAP ( $5 \mathrm{mg} / \mathrm{kg}$, ip) each day for 4 consecutive days ( $1^{\text {st }}$ treatment), followed by a second four-day treatment with the same amount of MAP beginning 26 days after the $1^{\text {st }}$ treatment regime. Physiological experiments were begun 7 days after the final injection of the $2^{\text {nd }}$ round of treatment (Fig. 1). Control rats were injected with physiological

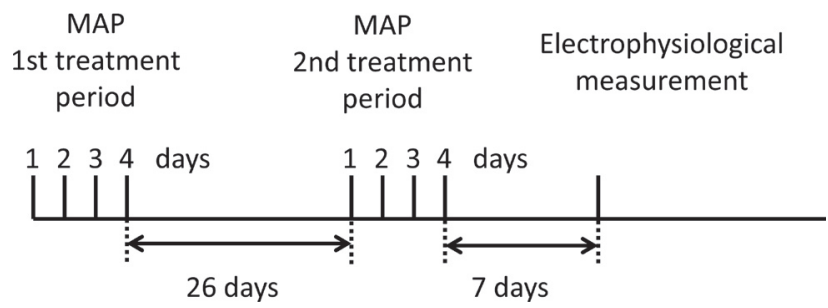

Figure 1. Schematic diagram of dosing and experimental schedule for chronic methamphetamine (MAP) treatment. The dosing regime involved two daily MAP treatment periods, followed by electrophysiological and morphological experiments. saline using the same dosing schedule as the MAP-treated rat group.

\section{Slice preparation}

Rats were deeply anesthetized with pentobarbital $(60 \mathrm{mg} / \mathrm{kg}$ i.p.) and euthanized by cervical dislocation. The brain was rapidly removed and soaked in a cold Krebs-Ringer solution, containing $126 \mathrm{mM} \mathrm{NaCl}, 5 \mathrm{mM} \mathrm{KCl}, 2.4 \mathrm{mM} \mathrm{CaCl}_{2}$, $1.3 \mathrm{mM} \mathrm{MgSO}_{4}, 1.26 \mathrm{mM} \mathrm{KH}_{2} \mathrm{PO}_{4}, 26 \mathrm{mM} \mathrm{NaHCO}_{3}$, $10 \mathrm{mM}$ D-glucose, saturated with $95 \% \mathrm{O}_{2}$ and $5 \% \mathrm{CO}_{2}$ (Hori et.al. 1988). The brain was bisected along the lateral olfactory tract (LOT) and the right cut surface placed down on moist filter paper, and cut into an even block by removal of the rostral and caudal parts. Slices of $400 \mu \mathrm{m}$ thickness were made along the LOT with a simple vibratome as described previously (Hori and Carpenter, 1994). Eight slices were obtained from each rat brain. Slices were incubated in a Krebs-Ringer solution for $2 \mathrm{~h}$ at $34^{\circ} \mathrm{C}$ to improve recovery from the injury. An individual slice was then placed on a fenestrated Plexiglas plate in a submerged recording chamber perfused with oxygenated external solution at $34^{\circ} \mathrm{C}$ at a flow rate of $3 \mathrm{ml} / \mathrm{min}$.

\section{Electrophysiological measurements}

As shown in Fig. 2A, a concentric stimulating electrode was placed within the LOT, and supramaximal electrical stimuli of $50 \mu$ s square-waves were applied at $0.05 \mathrm{~Hz}$. For recording of the population excitatory postsynaptic potential (field EPSP), a low-resistance glass micropipette (1 to $2 \mu \mathrm{m}$ tip diameter) filled with Ringer-Krebs solution was positioned in the dendritic tree of the pyramidal cell body. Electrical stimuli of $100 \mathrm{~Hz}$ were given to LOT for one second to induce LTP. Recording of intracellular membrane potentials in slice preparation were made with an approximately $80 \mathrm{M} \Omega$ conventional glass microelectrode filled with $2 \mathrm{M}$ potassium acetate. The glass microelectrode was connected to a DC amplifier (Neuro Data) and electrode resistance was nulled with the bridge circuit. Input resistance was measured using small current injections to elicit responses from $+10 \mathrm{mV}$ to $-20 \mathrm{mV}$ around the resting potential, to avoid rectification responses. The change in action potential threshold was not measured. AMPA and NMDA were ionophoretically applied to the dendrite trees during intracellular recordings. Ionophoresis was performed by Neurosphere Model $8 \mathrm{H}-2$ control unit applying an electrical pulse for $1 \mathrm{~s}$ every $30 \mathrm{~s}$ to a multi-electrode filled with AMPA or NMDA (Hori et al. 1988). For morphological analysis, Lucifer yellow $\mathrm{CH}$ (Sigma, 10\% in distilled water) was injected into a cell body through a different electrode (OD, $1.5 \mu \mathrm{m}$; ID, $0.9 \mu \mathrm{m}$; electrode resistance, 30-50 M 2 ) by the application of $250 \mathrm{~ms}$ and $2 \mathrm{nA}$ negative current pulses at $2 \mathrm{~Hz}$ for $1.5-2 \mathrm{~min}$. 


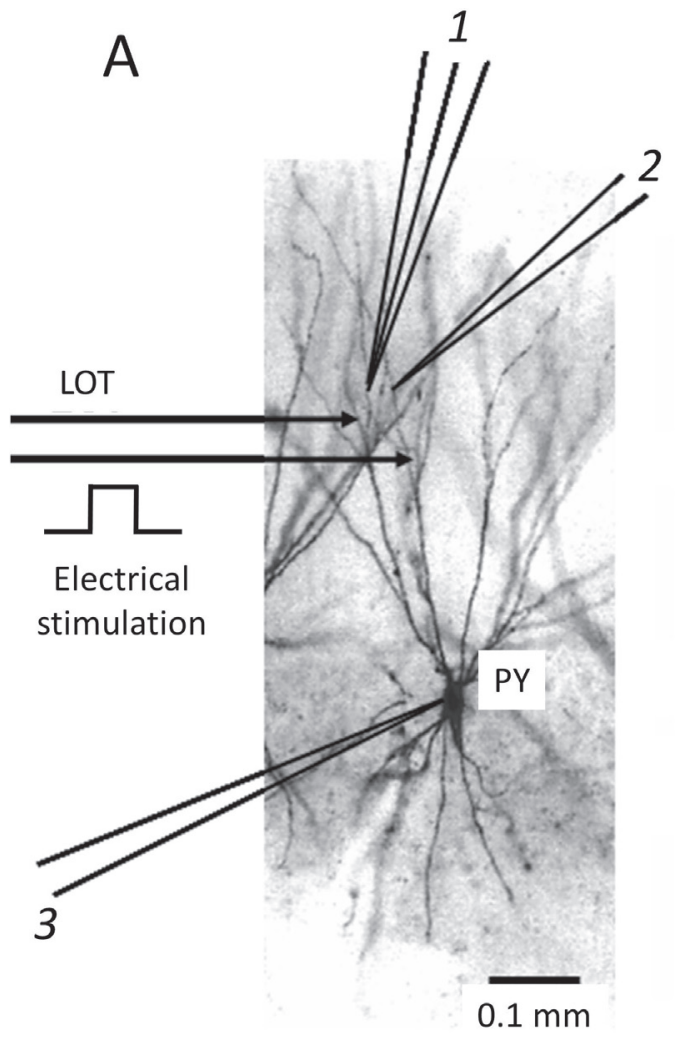

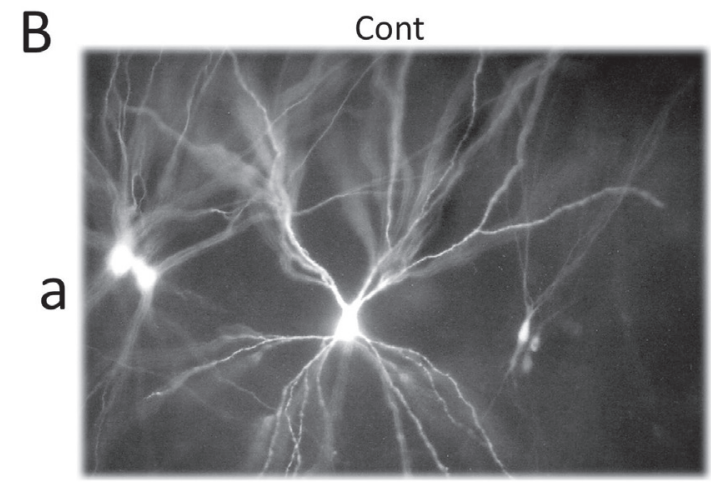

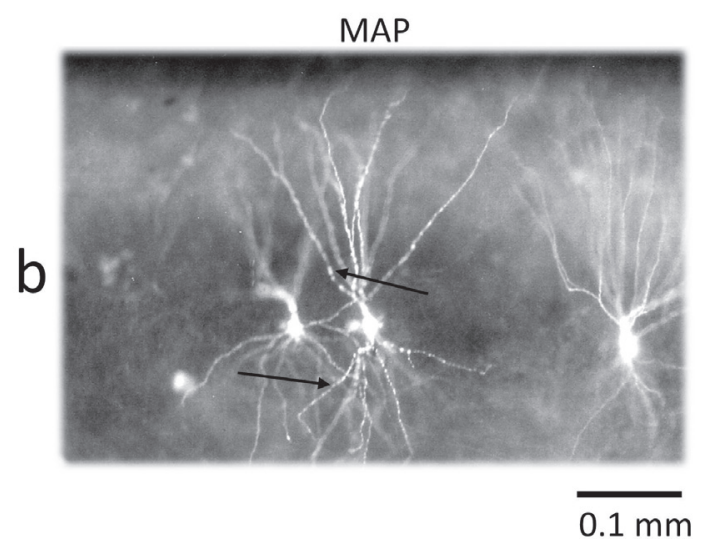

Figure 2. A. Photomicrograph of rat piriform cortex with labelled pyramidal neuron (PY) and showing schematic depiction of electrophysiological recordings with ionophoretic micro electrode (1), extracellular recording electrode (2), intracellular recording electrode (3) and stimulation of lateral olfactory tract (LOT). B. Pyramidal neurons in piriform cortex slices labelled by Lucifer yellow. Lucifer yellow was injected electrophoretically via a glass microelectrode, and the slice was subsequently fixed it in $4 \%$ para-formaldehyde. Neurons were observed under a fluorescence microscope, with images digitized and stored on hard disk, as in our previous papers (Hori et al. 2001, 2002, 2010). a. Typical morphological features of control rat pyramidal neurons. b. Typical features of pyramidal neurons of MAP-treated rats, including dendritic blebs (arrows). Scale bar is $0.1 \mathrm{~mm}$. Similar results were observed in other 4-6 slice preparations. Cont, control; MAP, methamphetamine.

\section{Results}

Rats maintained a constant body weight of about $250 \mathrm{~g}$ during the chronic MAP or saline treatment periods. In chronically MAP-treated rats, some sensitizations as evidenced by increased movement and sniffing were observed. Membrane properties of pyramidal neuron were recorded with conventional glass microelectrodes (Fig. 2A, “3”), synaptic field responses in dendritic layers recorded extracellularly (Fig. 2A, "2") in response to LOT stimulation and AMPA and NMDA receptor responses recorded intracellularly after iontophoretic application of these ligands to dendrites (Fig. 2A, "1"). Morphology was revealed by filling neurons with fluorescent Lucifer yellow, which extensively diffused into the neurons so as to identify soma and dendrites (Fig. 2B). Chronically MAP-treated rats showed some apparent blebbing of pyramidal cell dendrites that was absent in control rats (Fig. 2B). The average values and SD of pyramidal neuron membrane potential and input resistance in control neurons were $-64 \pm 9.2 \mathrm{mV}$ and $35 \pm 8.3$ $\mathrm{M} \Omega(n=5)$, respectively, while in MAP-treated rats both these values were significantly decreased to $-58 \pm 13.3 \mathrm{mV}$ and $22 \pm 6.1 \mathrm{M} \Omega(n=5)$, respectively (Fig. 3A). Figure 3Ba shows typical time course of LTP of excitatory synaptic field EPSPs recorded in control (Cont) and MAP-treated (MAP) neurons. The peak amplitude of the initial, transient post tetanic potentiation (PTP) was the same between control and MAP-treated rat neurons, but the amplitude of the prolonged LTP plateau phase was significantly smaller in MAP-treated rat neurons as compared to control neurons (Fig. 3Bb). Given the variability in the amplitude of synaptic potentials between different cells, Fig. 3B plots the extent of LTP (plateau phase in Fig. $3 \mathrm{Bb}$ ) relative to the control amplitude. 
A

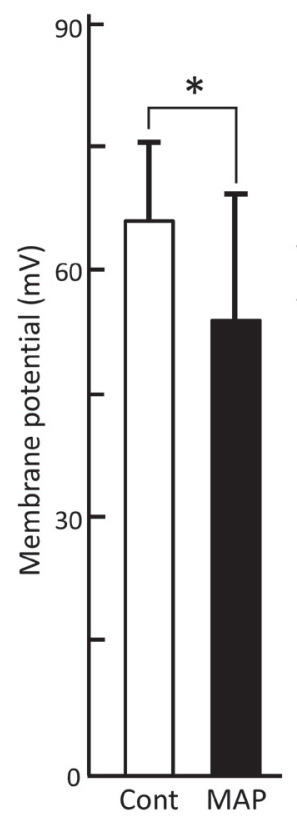

B

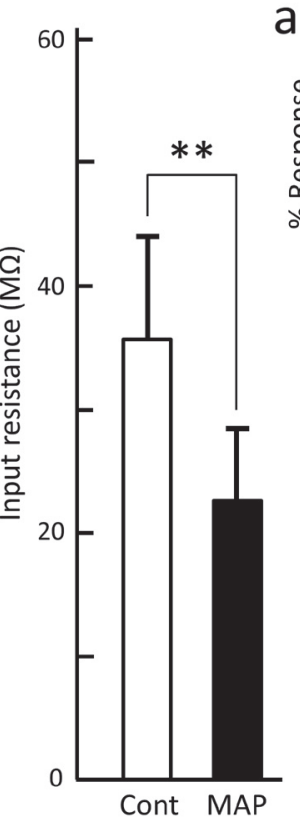

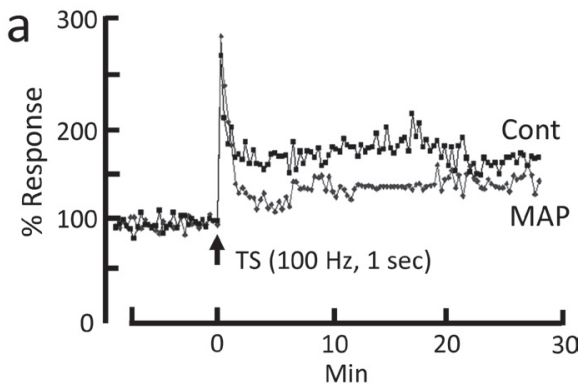

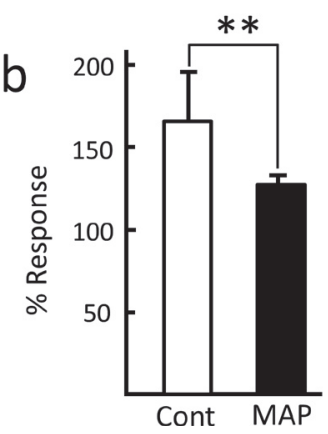

Figure 3. A. Averaged membrane potential and input resistance of pyramidal neurons from control (Cont) and chronic MAP-treated (MAP) rats. Data were obtained from 6-7 neurons. Vertical bar indicates mean \pm S.D. ${ }^{\star} p<0.05,{ }^{\star *} p<0.01$. Ba. Representative time course of the LTP of relative peak field EPSP amplitudes in response to tetanic LOT stimulation (TS, $100 \mathrm{~Hz}$ for $1 \mathrm{~s}$ ). Note the transient PTP in response to the tetanus, followed by a sustained LTP. Bb. The relative increase in the population response recorded 30 min following tetanic stimulation is significantly larger in slices from control rats (Cont) as compared to slices from chronic MAP-treated rats (MAP). Data were obtained from 7 neurons for control and 5 neurons for MAP-treated rats. ${ }^{*} p<0.01$. LOT, lateral olfactory tract ; LTP, long-term potentiation ; MAP, methamphetamine; PTP, transient post tetanic potentiation.

As NMDA and glutamate receptors are involved in mediating LTP at many synapses, we further studied the effects of chronic MAP treatment on the direct receptor response activated by ionophoretic application of AMPA and NMDA to the dendrite trees of pyramidal neurons (Fig. 2A). Figure $4 \mathrm{~A}$ shows typical responses obtained from control rat neurons and MAP-treated rat neurons (Fig. 4A) at different holding membrane potentials. When the membrane potential of control neurons was hyperpolarized, AMPA responses increased in amplitude while NMDA responses decreased in amplitude. The increase in AMPA responses is consistent with the increased driving force, while the NMDA response may decrease due to an increase in channel block by external $\mathrm{Mg}^{2+}$ at more negative potentials (e.g., Chen et al. 1999). Figure $4 \mathrm{~B}$ illustrates the measurement of the resting membrane potential response (a) and $10 \mathrm{mV}$ hyperpolarized membrane potential response (b), from which a response ratio $(b / a)$ was obtained. In control neurons the AMPA response ratio decreased by about $30 \%$ upon hyperpolarization, while the NMDA response increased by about 30\% upon hyperpolarization (Fig. 4B, $n=7$ ). In contrast, in MAP-treated rat neurons, the AMPA responses did not change much upon hyperpolarization, while the NMDA responses markedly increased upon hyperpolarization (Figs. 4A, B). Hence, this voltage-dependent profile was altered in MAP treated rats, including a loss of voltage-dependent block of NMDA response. Both the AMPA and NMDA response ratios were significantly different in control and MAP-treated rats (Fig. $4 \mathrm{~B}, n=7)$.

To further evaluate NMDA receptor function, we examined the effect of bath application of NMDA on the synaptic field EPSP. Figure 5 shows typical time course of effects of bath NMDA $\left(10^{-6} \mathrm{M}\right)$ field EPSPs evoked by supramaximal $50 \mu$ s square-wave pulses applied to LOT at $0.05 \mathrm{~Hz}$, in control (A) and MAP-treated (B) rat neurons. In control rats, the field EPSP amplitude decreased gradually with time after NMDA application, reaching a reduced steady-stay amplitude between about $10-40 \%$ of control over 15 min (Fig. 5A). In contrast, in all MAP-treated rat slice neurons, bath NMDA application completely eliminated the responses after $15 \mathrm{~min}$ of NMDA application (Fig. 5B). The elimination of synaptic response appeared slower and more variable, perhaps reflecting the decreased NMDA receptor response (as in Fig 4A). A transient facilitation was observed in some neurons during 
A
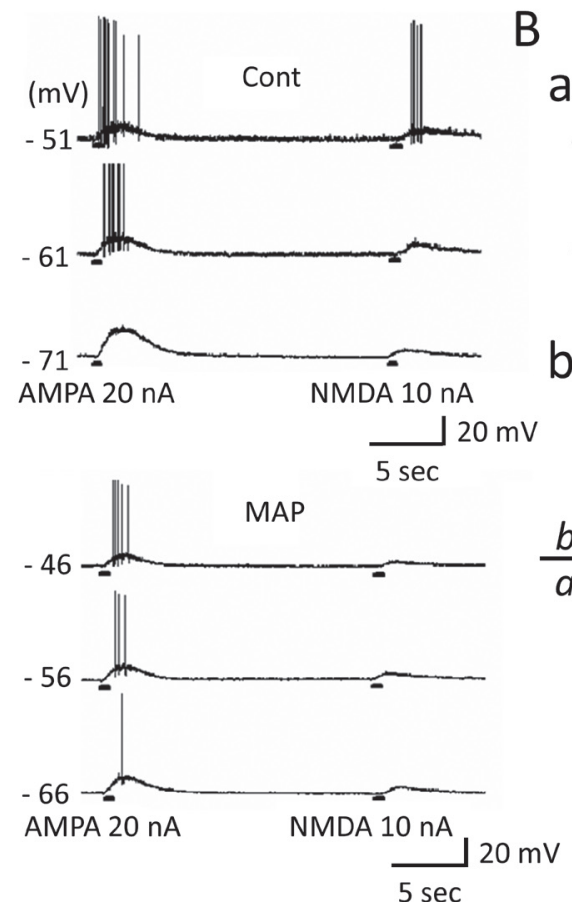

B a

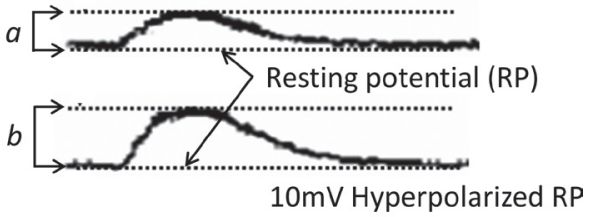

b

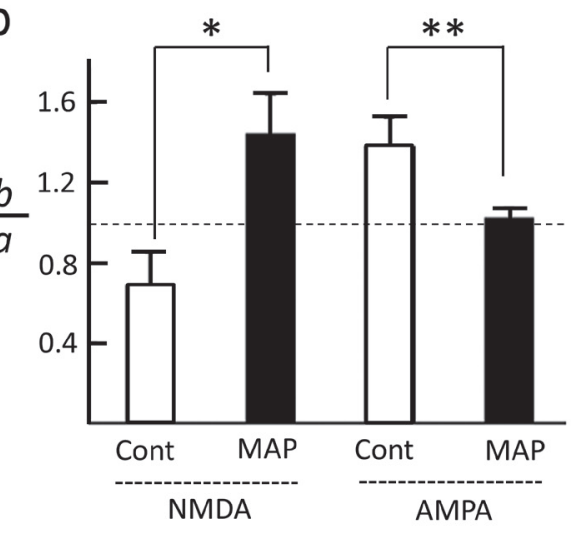

Figure 4. A. Intracellularly recorded AMPA and NMDA responses in control (Cont) and MAP-treated (MAP) rat neurons at different membrane potentials. NMDA and AMPA were applied by iontophoresis using $10 \mathrm{nA}$ and $20 \mathrm{nA}$ of current, respectively. In both graphs, the middle trace shows the recording at the resting membrane potential, the top trace is a membrane potential depolarized by $10 \mathrm{mV}$, while the lower trace is a membrane potential hyperpolarized by $10 \mathrm{mV}$. B. Quantification of the effect of membrane potential changes on the AMPA and NMDA responses. Schematic diagram illustrates how the ratio of hyperpolarized response to resting membrane potential response (b/a) was obtained. Upper panel (a) shows the resting membrane potential response, lower panel (b) shows the response when the membrane potential was hyperpolarized by $10 \mathrm{mV}$. Group data for the b/a ratio for the NMDA response (left) and the AMPA response (right) in control (Cont) and MAP treated rat neurons. Data were obtained from 7 neurons. ${ }^{*} p<0.05,{ }^{* *} p<0.01$.

the gradual disappearance of the response. The mechanisms of block and transient facilitation will require further study to explain, but the known decrease in $\mathrm{K}^{+}$channel currents in MAP-treated rodents (Wang et al. 2013) may contribute to

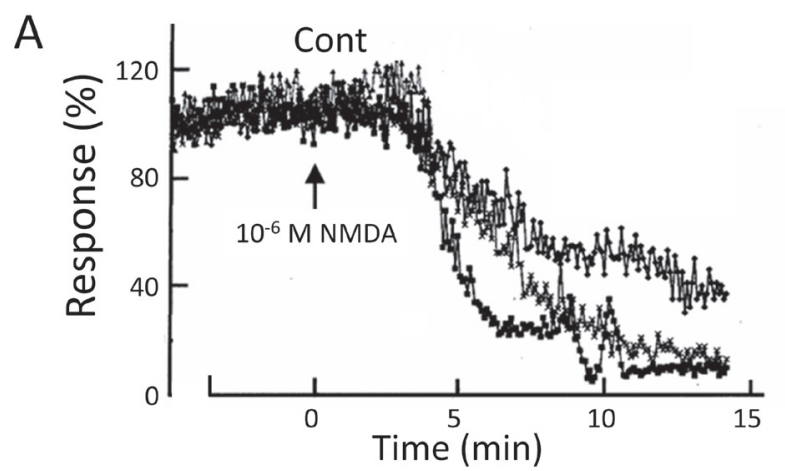

stabilize the membrane in the face of NMDA-induced depolarizations. Without such a stabilizing conductance, sudden depolarizations may transiently facilitate release before a loss of transmission due to further depolarization block.

Figure 5. Effects of NMDA on field synaptic responses evoked by supramaximal $50 \mu$ s square-wave pulses applied to the LOT at $0.05 \mathrm{~Hz}$, in control neurons $(\mathbf{A})$ and in MAP-treated neurons $(\mathbf{B})$. NMDA $\left(10^{-6} \mathrm{M}\right)$ was applied $5 \mathrm{~min}$ after evoking the synaptic response, as indicated by the arrow (time $=0 \mathrm{~min}$ ). Relative response amplitudes obtained from 3 neurons for $\mathrm{A}$, and 4 neurons for $\mathrm{B}$ are shown overlayed. 


\section{Discussion}

MAP is a powerfully addictive drug whose chronic use causes psychiatric complications for the users with associated social problems. Among the psychiatric symptoms, chronic MAP users have deficits in memory and learning. LTP is an electrophysiological response that is widely used to measure synaptic plasticity following high-frequency stimulation, and is a key event in the early steps of some forms of memory formation (Lynch 2004). Chronic MAP-treatment affects the formation of LTP in rodent hippocampal slices (Hori et al. 2010; Swant et al. 2010) and the present experiments show that LTP in piriform cortex pyramidal neurons in response to lateral olfactory tract stimulation is also impaired by chronic MAP. The reduced response to NMDA receptors and the altered voltage-dependence of the NMDA response may render this receptor unable to effectively induce this NMDA-dependent LTP (Kanter and Haberly 1990). However, dopamine receptors, along with NMDA receptors, are important in neurotoxicity of MAP (Kuribara and Uchihashi 1994). MAP exposure induces long-lasting alterations to NMDA and dopamine D1, D2 receptor function (Graham et al. 2013) and D1 receptors have an essential role in MAPinduced impairment of LTP in the hippocampus (Nabavi et al. 2013). The D1/D5 receptor agonist, SKF 38393, increases hippocampal LTP (Roggenhofer et al. 2013), suggesting MAP may act to inhibit D1 mediated. The learning of a reward for smell in rats depends on D1 receptors in the piriform cortex, and is also reduced with age (Garske et al.2013) and impaired LTP in the present study may also relate to MAP-induced altered D1 signaling. Interestingly, the extent of PTP was similar in control and MAP rats, suggesting that aspects of acute $\mathrm{Ca}^{2+}$-dependent presynaptic plasticity at this synapse are retained after chronic MAP (Zucker 1993).

We also observed apparent blebbing on both the apical and basal dendrites of MAP- treated rat piriform neurons. Similar morphological changes were also seen in our previous study on CA1 pyramidal cells in MAP-treated rats (Hori et al. 2010). The membrane potential and input resistance in MAP-treated rat neurons significantly decreased as compared to control neurons. The morphological changes we saw are indicative of cellular injury, and an injury induced non-selective "leak" current may contribute to the reduction of membrane potential and input resistance, as also suggested for CA1 neurons in our previous report (Hori et al. 2010). A more specific conductance change, such as an inhibition of the Ca-activated $\mathrm{K}$ channels may also contribute to the depolarization induced by chronic MAP (Wang et al. 2013).

Similar morphological and membrane potential changes were observed in hippocampal CA1 neurons after transient ischemia, which results in a complete loss of synaptic function over time (Hori and Carpenter 1994). These morphological and functional changes may also contribute to the loss of LTP seen in the present study, suggesting a more indirect effect of MAP rather than a direct effect on LTP mechanisms. LTP and learning of new tasks are both associated with increased growth and stabilization of dendritic spines (Wang et al. 2008; Hill and Zito 2013), and the morphological changes seen in the present study would be expected to impair dendritic growth and stabilization, and also to possible disrupt neural circuits and lead to functional defects (Frost and Cadet 2000).

When the membrane potential was hyperpolarized, the AMPA responses of control neurons became bigger while NMDA response decreased. This contrasted with MAPtreated rats in which the opposite directions of changes were seen. The mechanisms of this difference are unclear. As indicated above, this may reflect relief of voltage-dependent block of NMDA receptors, as reported previously in MAPtreated animals (Moriguchi et al. 2002) and in kainic acidinduced trauma (Chen et al. 1999). Alternatively, changes in morphology and in membrane properties may mean that the ability to maintain altered membrane potentials in neuronal dendrites is decreased in MAP-treated rats, with these potential dendritic changes may differentially affect the AMPA and NMDA responses. Functional changes in the subtypes or posttranslational modification of AMPA and NMDA receptors may also occur with chronic MAP treatment.

In conclusion, chronic MAP treatment results in a range of morphological, neuronal membrane and synaptic receptor effects that suggest neural circuit processing in dendrites and cell soma of piriform pyramidal neurons is impaired. Our results bear similarities to those observed at hippocampal synapses, suggesting effects of MAP treatment may impact on synaptic plasticity and circuit properties more widely than just at hippocampal synapses. These cellular and neural circuit changes may contribute also to changes of memory, learning, and social behaviors. The piriform cortex in particular may be involved in sensitization of olfactory behaviours in MAP-treated rats. Our studies provide an additional model to help understand the neural basis of such psychiatric symptoms.

Acknowledgments. The authors thank Dr. A. Moorhouse (University of New South Wales, Sydney, Australia) for valuable comments and critical reading of the manuscript. The authors also thank to Dr. M. Wakita (Kumamoto Kinoh Hospital, Kumamoto, Japan) for writing and graphical assistance.

Conflicts of interest. There are no conflicts of interest to disclose.

\section{Rererences}

Chen Y., Chad J. E., Cannon R. C., Wheal H. V. (1999): Reduced $\mathrm{Mg} 2+$ blockade of synaptically activated $\mathrm{n}$-methyl-d-aspartate 
receptor-channels in CA1 pyramidal neurons in kainic acidlesioned rat hippocampus. Neurosci. 88, 727-739 http://dx.doi.org/10.1016/S0306-4522(98)00253-X

Fasihpour B., Molavi S., Shariat S. V. (2013): Clinical features of inpatients with methamphetamine-induced psychosis. J. Ment. Health 22, 341-349 http://dx.doi.org/10.3109/09638237.2012.745184

Frost D. O., Cadet J. L. (2000): Effects of methamphetamine-induced neurotoxicity on the development of neural circuitry: a hypothesis. Brain Res. Rev. 34, 103-118 http://dx.doi.org/10.1016/S0165-0173(00)00042-4

Garske A. K., Lawyer C. R., Peterson B. M., Illig K. R. (2013): Adolescent changes in dopamine D1 receptor expression in orbitofrontal cortex and piriform cortex accompany an associative learning deficit. PLoS One 8, e56191 http://dx.doi.org/10.1371/journal.pone.0056191

Gonçalves J., Baptista S., Olesen M. V., Fontes-Ribeiro C., Malva J. O., Woldbye D. P., Silva A. P. (2012): Methamphetamineinduced changes in the mice hippocampal neuropeptide $\mathrm{Y}$ system: implications for memory impairment. J. Neurochem. 123, 1041-1053 http://dx.doi.org/10.1111/jnc.12052

Graham D. L., Amos-Kroohs R. M., Braun A. A., Grace C. E., Schaefer T. L., Skelton M. R., Williams M. T., Vorhees C. V. (2013): Neonatal +-methamphetamine exposure in rats alters adult locomotor responses to dopamine D1 and D2 agonists and to a glutamate NMDA receptor antagonist, but not to serotonin agonists. Int. J. Neuropsychopharmacol. 16, 377-391 http://dx.doi.org/10.1017/S1461145712000144

Han W., Wang F., Qi J., Wang F., Zhang L., Zhao S., Song M., Wu C., Yang J. (2012): NMDA receptors in the medial prefrontal cortex and the dorsal hippocampus regulate methamphetamine-induced hyperactivity and extracellular amino acid release in mice. Behav. Brain Res. 232, 44-52

http://dx.doi.org/10.1016/j.bbr.2012.03.038

Hill T. C., Zito K. (2013): LTP-induced long-term stabilization of individual nascent dendritic spines. J. Neurosci. 33, 678-686 http://dx.doi.org/10.1523/JNEUROSCI.1404-12.2013

Hori N., Akaike N., Carpenter D. O. (1988): Piriform cortex brain slices: techniques for isolation of synaptic inputs. J. Neurosci. Methods 25, 197-208 http://dx.doi.org/10.1016/0165-0270(88)90134-3

Hori N., Carpenter D. O. (1994): Functional and morphological changes induced by transient in vivo ischemia. Exp. Neurol. 129, 279-289 http://dx.doi.org/10.1006/exnr.1994.1170

Hori N., Tan Y., Strominger N., Carpenter D. O. (2001): Intracellular activity of rat spinal cord motoneurons in slices. J. Neurosci. Methods 112, 185-191 http://dx.doi.org/10.1016/S0165-0270(01)00467-8

Hori N., Tan Y., Strominger N., Carpenter D. O. (2002): Rat motoneuron cell death in development correlates with loss of Nmethyl-D-aspartate receptors. Neurosci. Lett. 330, 131-134 http://dx.doi.org/10.1016/S0304-3940(02)00749-8

Hori N., Kadota M. T., Watanabe M., Ito Y., Akaike N., Carpenter D. O. (2010): Neurotoxic effects of methamphetamine on rat hippocampus pyramidal neurons. Cell Mol. Neurobiol. 30, 849-856 http://dx.doi.org/10.1007/s10571-010-9512-1

Ishikawa A., Kadota T., Kadota K., Matsumura H., Nakamura S. (2005): Essential role of D1 but not D2 receptors in methamphetamine-induced impairment of long-term potentiation in hippocampal-prefrontal cortex pathway. Eur. J. Neurosci. 22, 1713-1719 http://dx.doi.org/10.1111/j.1460-9568.2005.04332.x

Kanter E. D., Haberly L. B. (1990): NMDA-dependent induction of long-term potentiation in afferent and association fiber systems of piriform cortex in vitro. Brain Res. 525, 175-179 http://dx.doi.org/10.1016/0006-8993(90)91337-G

Kitanaka J., Kitanaka N., Tatsuta T., Hall F. S., Uhl G. R., Tanaka K., Nishiyama N., Morita Y., Takemura M. (2009): Sigma1 receptor antagonists determine the behavioral pattern of the methamphetamine-induced stereotypy in mice. Psychopharmacology (Berl.) 203, 781-792 http://dx.doi.org/10.1007/s00213-008-1425-z

Kuribara H., Uchihashi Y. (1994): Effects of dopamine antagonism on methamphetamine sensitization: evaluation by ambulatory activity in mice. Pharmacol. Biochem. Behav. 47, 101-106 http://dx.doi.org/10.1016/0091-3057(94)90117-1

Lynch M. A. (2004): Long-term potentiation and memory. Physiol. Rev. 84, 87-136 http://dx.doi.org/10.1152/physrev.00014.2003

Linster C., Hasselmo M. E. (2001): Neuromodulation and the functional dynamics of piriform cortex. Chem. Senses 26, 585-594 http://dx.doi.org/10.1093/chemse/26.5.585

Moriguchi, S., Watanabe S., Kita H., Nakanishi H. (2002): Enhancement of N-methyl- D-aspartate receptor-mediated excitatory postsynaptic potentials in the neostriatum after methamphetamine sensitization. An in vitro slice study. Exp. Brain Res. 144, 238-246 http://dx.doi.org/10.1007/s00221-002-1039-3

Nabavi S., Kessels H. W., Alfonso S., Aow J., Fox R., Malinow R. (2013): Metabotropic NMDA receptor function is required for NMDA receptor-dependent long-term depression. Proc. Natl. Acad. Sci. USA 110, 4027-4032 http://dx.doi.org/10.1073/pnas.1219454110

Ohmori T., Abekawa T., Muraki A., Koyama T. (1994): Competitive and noncompetitive NMDA antagonists block sensitization to methamphetamine. Pharmacol. Biochem. Behav. 48, $587-591$ http://dx.doi.org/10.1016/0091-3057(94)90318-2

Roggenhofer E., Fidzinski P., Shor O., Behr J. (2013): Reduced threshold for induction of LTP by activation of dopamine D1/D5 receptors at hippocampal CA1-subiculum synapses. PLoS One 8, e62520 http://dx.doi.org/10.1371/journal.pone.0062520

Rusyniak D. E. (2013): Neurologic manifestations of chronic methamphetamine abuse. Psychiatr. Clin. North Am. 36, 261-275 http://dx.doi.org/10.1016/j.psc.2013.02.005

Schröder N., O’Dell S. J., Marshall J. F. (2003): Neurotoxic methamphetamine regimen severely impairs recognition memory in rats. Synapse 49, 89-96 http://dx.doi.org/10.1002/syn.10210

Swant J., Chirwa S., Stanwood G., Khoshbouei H. (2010): Methamphetamine reduces LTP and increases baseline synaptic 
transmission in the CA1 region of mouse hippocampus. PLoS One 5, e11382

http://dx.doi.org/10.1371/journal.pone.0011382

Thomas D. M., Kuhn D. M. (2005): MK-801 and dextromethorphan block microglial activation and protect against methamphetamine-induced neurotoxicity. Brain Res. 1050, 190-198

http://dx.doi.org/10.1016/j.brainres.2005.05.049

Wang Y. J., Chan M. H., Chen H. H. (2013): Methamphetamine inhibits voltage-gated potassium currents in NG108-15 cells: possible contribution of large-conductance calcium-activated potassium channels. Toxicol. Lett. 223,139-145

http://dx.doi.org/10.1016/j.toxlet.2013.08.021
Wang X. B., Bozdagi O., Nikitczuk J. S., Zhai Z. W., Zhou Q., Huntley G. W. (2008): Extracellular proteolysis by matrix metalloproteinase-9 drives dendritic spine enlargement and long-term potentiation coordinately. Proc. Natl. Acad. Sci. USA 105, 19520-19525 http://dx.doi.org/10.1073/pnas.0807248105

Zucker R. S. (1993): Calcium and transmitter release. J. Physiol Paris 87, 25-36 http://dx.doi.org/10.1016/0928-4257(93)90021-K

Received: February 6, 2014

Final version accepted: July 24, 2014

First published online: November 4, 2014 